Marquette University

e-Publications@Marquette

Biological Sciences Faculty Research and

Publications

Biological Sciences, Department of

2-1-1984

Financial Exigency: Need It Affect the Quality of Biology Curricula?

Robert G. Thomson

Marquette University

Peter Abramoff

Marquette University

Published version. The American Biology Teacher, Vol. 46, No. 2 (February 1984): 99-101. DOI. (C) 1984 University of California Press. Used with permission. 


\title{
Financial Exigency: Need It Affect the Quality of Biology Curricula?
}

\author{
Robert G. Thomson \\ Peter Abramoff
}
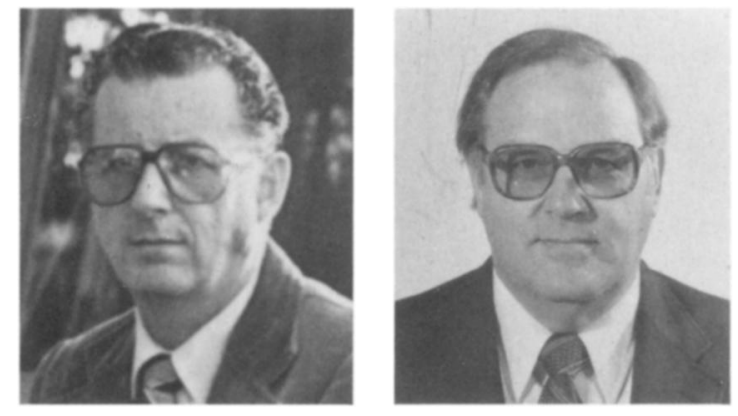

Robert G. Thomson is Associate Professor and Assistant Chairman, Department of Biology, at Marquette University, Milwaukee, WI 53233, where he has taught since 1968 . He holds a B.S. in botany from University of Wisconsin-Milwaukee, and an M.S. in biology and a Ph.D. in plant development from Marquette. He is a member of the Association for Biology Laboratory Education and the National Association of Advisors for the Health Professions and has served as an NABT reviewer. Peter Abramoff is Chairman and Wehr Professor of Biology at Marquette University. He received his B.A. from Assumption College of the University of Western Ontario, his M.S. from University of Detroit, and his Ph.D. from University of Wisconsin. He was named Outstanding Educator for America in 1971 and Wehr Distinguished Professor of Biology in 1978. He belongs to many professional associations and serves as a consultant to several other organizations, including the U.S. Office of Biological Education and the NSF program on Undergraduate Education in Science. Drs. Thomson and Abramoff are coauthors of several books as well as authors individually.

Declining enrollments and financial restraints require that science departments seek ways to meet academic commitments within the framework of reduced budgets and faculty resources without sacrificing quality programs. The following describes our evaluation of the role of the laboratory in the undergraduate biology curriculum and the positive effects achieved on our academic, financial, and faculty resources by separating labs from lecture courses and reducing the number of labs required for majors and nonmajors.

Several years ago we experienced increased enrollments coupled with only modest increases in funds to deliver our undergraduate instructional programs. To resolve this problem we developed a new approach to the role of lecture and laboratory courses for our biology majors, the nonmajor, and the students in the allied health programs serviced by our department. The changes effected by us then would appear to be equally appropriate in today's economy when inflationary pressures and a decline in students make it imperative that departments look to ways to meet their academic commitments within the framework of declining budgets and faculty resources.

\section{The Old Program and Its Problems}

Marquette University's undergraduate biology curriculum formerly consisted of a one-year introductory general biology course; upper level core courses in cell biology, environmental biology, genetics, and developmental biology; and several elective courses. Most of these were coupled lecture-laboratory courses. The biology major took all of the core courses plus several biology electives. The introductory course was taken by both majors and nonmajors to satisfy their science requirement. Enrollment in the introductory course ranged from 800-900 students while enrollments in the core courses varied from 100-125 students. Although significant and meaningful instruction could be provided for large numbers of students in a lecture course, serious difficulties were encountered in delivering adequate laboratory programs to accommodate such enrollments. These included the scheduling of large numbers of laboratory sections (35/semester in the introductory course and up to 17 in the core and elective courses), provision for adequate logistical support for the laboratory courses, and recruitment of large numbers of graduate students to supervise these laboratory sections.

As we examined the role of the laboratory in an undergraduate curriculum, we concluded that labs were primarily used to illustrate selected principles previously introduced in the lecture, to acquaint the student with a multiplicity of techniques, and to illustrate the diversity of living organisms. Attempts at breadth of coverage had so formalized laboratory work that it had largely become an exercise in manual dex- 
terity rather than an introduction to the principles of biology. We became convinced that a more effective use of the laboratory work was needed.

\section{Redefining the Role of the Lab}

From a careful evaluation of the role of the undergraduate laboratory we concluded that such experiences should develop the students' critical thinking and creative abilities and increase their appreciation of the mechanisms by which biologists obtain and analyze information. Use of the laboratory in this fashion was not compatible with the large number of sections in our courses. It became obvious that a laboratory coupled with every lecture course was not needed to accomplish this objective. We rationalized that a few well-defined and carefully delivered laboratory experiences would meet these objectives.

\section{Uncoupling and Reducing the Number of Labs Required}

Therefore we created separate lecture and laboratory courses and reduced the total number of laboratory courses required for a biology major. Following an analysis of the faculty strengths in our department, we elected to offer one laboratory course at the introductory level and six at the upper division level (cell biology, genetics, physiology, development, plant morphology, and microbiology). Each laboratory course meets weekly for one hour of lecture-discussion and four hours of laboratory work, and is offered only once during the academic year. Biology majors are required to complete any two upper division laboratory courses beyond the introductory course.

The most significant change involved uncoupling the laboratory from the introductory biology course and reducing the two-semester laboratory requirement to a single laboratory course that could be taken either semester. This course, which meets weekly for one hour of lecture-discussion and a three-hour laboratory period, provides insights into experimental design and data analysis, selected instrumentation, basic methodologies, and such laboratory skills as pipeting, serial dilutions, and staining procedures.

Laboratory studies, prior to these changes, were largely oriented to the examination of various phyla, dissection, and repetition of rather simplistic exercises, the answers and conclusions of which either eluded the student completely or were understood before the exercise began. In the introductory laboratory described here, in contrast, students examine variables affecting respiration, and design and build their own respirometers, design and carry out the experimental protocol, and collect and analyze their data. Selected methodologies include preparation of media, various procedures for isolating microorganisms, spec- trophotometric analysis of protein solutions, and procedures for artificially inducing ovulation and development in tunicates, sea urchins, and frogs.

From such preliminary experiences, students progress to more sophisticated experiments in upper division labs. These includes such studies as the isolation, partial purification, and assay of enzymes, analysis of antigen binding cells by rosette formation, photoperiod studies of induction and initiation of flowering, in vitro culture of root and shoot apices, and hormonal control of smooth muscle contraction.

This introductory laboratory course, required of the biology major and optional for the nonmajor, fulfills the "biology with lab" requirement of medical, dental, and other health-related programs.

\section{Benefits of New Curriculum}

This core laboratory program has had several beneficial effects on our physical, financial, and faculty resources. We reduced the total number of laboratory sections offered each week from 52 to 16 . As a result, we were able to schedule laboratory courses without competing for space with a large number of other laboratory courses. Space was provided for the exclusive use of each upper division laboratory course which meant that each could be designed to meet the specific needs of that course. For example, in the developmental biology laboratory, we installed egg incubators and marine aquaria; in the cell biology laboratory we added a laminar flow hood, refrigerated centrifuges, and $\mathrm{a} \mathrm{C}_{2}$ incubator; in the physiology lab we incorporated physiographs, oscilloscopes, pneumographs, and exercycles. We even found that we no longer needed all of our laboratories for teaching purposes and were able to convert two of the smaller rooms into graduate student offices.

\section{Separating Teaching Responsibilities}

An important consequence of uncoupling and reducing the number of courses was redelegation of the teaching responsibilities of our faculty. Faculty no longer split their efforts as was the case when they were responsible for both the lecture and laboratory aspects of a coupled course. In evaluating instructional loads, teaching a laboratory course now carried the same academic recognition as a lecture course. More importantly, our students have direct contact with the faculty member in the laboratory who is always in the laboratory along with a teaching assistant. The benefits that accrue to the students, as well as the teaching assistant, are obvious.

Such a reorganization of our curriculum led to a reduction in the number of students enrolled in these laboratory courses. Whereas the coupled lecturelaboratory courses carried enrollments of 100-125 
students, this has been reduced to a very manageable class size of 30-36 students. We rarely need to schedule more than two sections of 10-18 students each for any of our laboratory courses.

\section{Centralized Equipment Facility}

The delivery of coupled lecture-laboratory courses required that adequate instructional equipment and supplies be available to meet the needs of large numbers of sections. Equipment was usually assigned to specific teaching laboratories and was unavailable to other courses even when the equipment was not being used. This led to excessive duplication of equipment. For example, several teaching laboratories were each equipped with complete sets of microscopes, water baths, $\mathrm{pH}$ meters, and so forth. Evaluation of our equipment utilization prior to separation of laboratories showed that we rarely used the same types of equipment at the same time. Realizing this, we established a central facility to store instructional equipment when it was not being used. Inventory procedures permitted us to know exactly what types and how many pieces of equipment we had, gave us control over the movement of this equipment, and proved to be an invaluable asset for insurance purposes.

Financial savings resulting from the unnecessary duplication of equipment proved to be substantial enough to permit the hiring of a full-time equipment supervisor in place of the part-time person initially used to supervise this facility. Additional savings were realized as this person learned to service our instructional equipment and substantially reduced the rate and extent of classroom damage and considerably extended the useful life of this equipment. From the savings obtained through uncoupling and reducing the number of laboratories we also found that we were able to purchase more sophisticated equipment and instructional materials.

In summary, when we started looking at revision of our instructional program we were not at all certain that it would be possible to replace our traditional program without diluting the quality and scope of our other offerings or expending greater faculty and financial resources in its operation. In the process of developing a program centered around a core curriculum with laboratory courses uncoupled from lecture courses we found that we achieved greater flexibility, increased student-faculty contact, provided specialized facilities for each laboratory course, decreased the number of students per laboratory section, purchased more sophisticated equipment, hired an equipment manager, and reduced the number of courses taught by our faculty. Such benefits have been achieved even though we still have large numbers of students in our program and limited resources.

\section{Answering Their Questions}

from p. 91

ALTER, J., and SCALES, P. 1979. An analysis of U.S. sex education programs and evaluation methods. Springfield, Va.: National Technical Information Service.

and SCALES, P. 1981. An analysis of state guidelines for sex education instruction in public schools. Family Relations 30(2):229-237.

KOHLBERG, L. (ed.) 1973. Collected papers on moral development and moral education. Cambridge, Mass.: Harvard University, Laboratory for Human Development.

McNAB, W.L. 1981. Advocating elementary sex education. Health Education 12(5):22-25.

MAHONEY, E.R. 1979. Sex education in the public schools: A discriminant analysis of chracteristics of pro and anti individuals. Journal of Sex Research 15(4):264-275.

NAMEROW, P.B., and PHILIBER, S.G. 1982. The effectiveness of contraceptive programs for teenagers. Journal of Adolescent Health Care 2(3):189-198.

NEW JERSEY STATE DEPARTMENT OF EDUCATION. 1981. New Jersey family life guidelines. Trenton, N.J.:N.J. State Department of Education.

PENICK, J.E., and YAGER, R.E. 1983. The search for excellence in science education. Phi Delta Kappan 64(9):621-623.

RATHS, L.E., HARMIN, M., and SIMON, S.B. 1966. Values and teaching: Working with values in the classroom. Columbus, Ohio: Charles E. Merrill.

SCALES, P. 1981. Where is sexuality education today? Independent School 41(1):10-12.

1982. Values' roles in sexuality education. Planned Parenthood Review 2(3):6-8.

SHAH, F., and ZELNICK, M. 1981. Parent and peer influence on sexual behavior, contraceptive use, and pregnancy experience of young women. Journal of Marriage and the Family 43(2):339-348.

SIMON, S.B., HOWE, L.W., and KIRSCHENBAUM, H. 1972. Values clarification: A handbook of practical strategies for teachers and students. New York: Hart.

SIMON, S.B., and OLDS, S.W. 1977. Helping your child learn right from wrong: A guide to values clarification. New York: McGraw-Hill.

STATE COMMISSION ON SEX EDUCATION. 1974. Proposed guidelines for sex education in the Swedish school system: A summary of the recommendations contained in the official report. Stockholm: The State Commission on Sex Education.

\section{Science Teaching Insights}

from p. 86

LEONARD, W.H. 1981. Laboratory instruction is on trial. American Biology Teacher 43(8):445-7.

MANTEUFFEL, M.S., and VON BLUM, R. 1979. A model for training biology teaching assistants. American Biology Teacher 41(8):476-9.

MOLL, M., and ALLEN, R.D. 1982. Student and graduate teaching assistant response to investigative laboratories. Journal of College Science Teaching 11(4):219-22.

RENFREW, M.M., and MOELLER, T. 1978. The training of teaching assistants in chemistry. Journal of Chemical Education 55(6):386-8.

SHERIDAN, P. 1978. Formax preserved birds. American Biology Teacher 40(10):22-2. 